\title{
Thermal Boundary Conductance between refractory metal carbides and diamond
}

\author{
Christian Monachon ${ }^{\mathrm{a}, *}$, Ludger Weber ${ }^{\mathrm{a}}$ \\ ${ }^{a}$ Laboratoire de Métallurgie Mécanique, Ecole Polytechnique Fédérale de Lausanne, \\ Lausanne, Switzerland
}

\begin{abstract}
The Thermal Boundary Conductance (TBC) between thin films of Cr, Mo, $\mathrm{Nb}$ and $\mathrm{W}$ and diamond substrates has been measured using time domain thermoreflectance before and after a high-vacuum heat treatment at $800{ }^{\circ} \mathrm{C}$ for $2 \mathrm{~h}$. While no signs of carbide formation could be detected in as-deposited layers by Scanning Transmission Electron Microscopy Energy Dispersive Xray spectroscopy (STEM-EDX) elemental analysis, the heat treatment led to partial (W, Mo) or full conversion $(\mathrm{Cr}, \mathrm{Nb})$ of the film into carbide. The measured TBC values on as-deposited samples of 315, 220, 220 and 205 $\mathrm{MWm}^{-2} \mathrm{~K}^{-1}$ measured for, respectively, the $\mathrm{Cr}$, Mo, Nb and $\mathrm{W}$ samples, were found to not be significantly altered by the heat treatment.
\end{abstract}

Keywords: Time Domain ThermoReflectance, Thermal Boundary Conductance, Metal Matrix Composites, Molybdenum, Tungsten, Chromium, Niobium, Diamond, thermal management materials

\section{Introduction}

Diamond reinforced Metal Matrix Composites (MMC) have come into research focus in the past few years as they could potentially be used as highly efficient, thermal expansion-matched heat sinks in microelectronics applications[1]. Indeed, mixing diamond with highly thermally conductive metals such as copper, silver or aluminum allows for composites with a ther-

*. Corresponding author

Email addresses: christian.monachon@a3.epfl.ch (Christian Monachon), ludger.weber@epfl.ch (Ludger Weber) 
mal conductivity up to $985 \mathrm{Wm}^{-1} \mathrm{~K}^{-1}[2]$ and a Coefficient of Thermal Expansion (CTE) lying between 4 and $8 \mathrm{ppmK}^{-1}$, covering the CTE range of typical semiconductors in high heat dissipation applications.

One of the key factors that controls the upper limit of the achievable composite conductivity are the diamond/metal interfaces. Indeed, their quality directly influences the diamond/metal Thermal Boundary Conductance $(\mathrm{TBC})[5,6]$, the effect of which significantly increases with decreasing particle size[7].

In $\mathrm{Al}$ matrix composites, good results are obtained using $\mathrm{Al}$ or $\mathrm{Al} / \mathrm{Si}$ alloys [35] because good adhesion is obtained between the matrix metal and the diamond powder provided the composite processing provides sufficient time at high temperature to form strong interfaces[8]. For pure copper and silver, however, the chemical affinity between the metal and carbon is insufficient to form strong interfaces and hence thermal conductivity of composites using pure metals are rather low, typically significantly below the pure metal's conductivity. This can be overcome by either (i) activating the diamond surface [9], by (ii) adding alloying elements with higher affinity to carbon, or (iii) by coating the diamond with an adhesion layer. For $\mathrm{Cu}$, adding alloying elements such as B, $\mathrm{Cr}[6,10]$, or $\mathrm{Zr}[11]$, to the matrix metal, yield high composite thermal conductivities, presumably through the formation of a small amount of interfacial carbide[12]. Coating the powder before processing it into a composite has been achieved by sputtering of $\mathrm{Mo}[13]$, by the molten salt route [14,15], or by vapor phase deposition of $\mathrm{W}[16]$. The latter process has led to particularly high thermal conductivity of up to $907 \mathrm{Wm}^{-1} \mathrm{~K}^{-1}$ for 100nm thick coatings, while thicker coatings reduced the beneficial effect. It is however unclear whether the conductivity improvement achieved when a carbide is present at the matrix/filler interface is due to an improved interfacial adhesion[17, 18], or to the presence of a phase with phononic properties intermediate between filler and matrix[19, 20], as these effects have both been shown to improve the interface conductance.

A convenient method to measure the TBC at a metal/dielectric interface directly is Time-Domain ThermoReflectance[21, 22] (TDTR). It uses samples consisting of thin metallic layers directly deposited onto dielectric substrates, hence having the ability to measure the conductance of a single interface. Using this technique on metal/diamond systems, the diamond surface chemistry was shown to have a strong impact on the TBC between diamond and metals [23-25]. Hydrogen-terminated diamond surfaces were found to always be detrimental to obtaining high $\mathrm{TBC}[18,24]$. This was rationalized 
by the fact that hydrogen termination also lowers the metal/diamond work of adhesion, thereby weakening the bonds between metal and diamond[18]. By using an oxygen plasma treatment of the diamond surface, it was shown that both a good adhesion and a high TBC can be obtained between a metal and diamond[24, 25]. Good adhesion was also shown to be essential to obtain a good TBC even after a heat treatment[26], because such a treatment would otherwise be ineffective or, worse, detach the metallic layer, due to differences in Coefficient of Thermal Expansion between layer and substrate.

We present here an investigation of the effect on TBC of transforming layers of $\mathrm{W}, \mathrm{Mo}, \mathrm{Nb}$ and $\mathrm{Cr}$ deposited on diamond into their respective carbides by heat treating them in high vacuum. The various elements are chosen as the formation of a carbide would provide an interface layer with either lower $(\mathrm{Cr})$, comparable (Mo) or higher (W, Nb) Debye temperature than the metal, the latter being a first order indicator for the match of the phonon density of states on either side of the interface intervening in phonon elastic scattering theory at interfaces. The TBCs with the diamond substrate are measured by TDTR. The metallic layer composition is determined before and after the heat treatment by Transmission Electron Microscopy (TEM) and the bonding states at the interface are evaluated by X-ray Photoelectron Spectroscopy (XPS). The results are discussed in the light of the effectiveness of carbide formers in improving the thermal conductivity of diamond-based MMCs and to investigate the predominance of bonding or phonon energy distribution on TBC.

\section{Experimental}

\subsection{Sample preparation}

Diamond substrates were purchased from Element 6 (Shannon Airport, Shannon, Co. Clare, Ireland, MWS L25, [100] surface orientation). The [100]oriented stones were factory-polished, but were further polished using diamond suspensions of 6 , followed by $1 \mu \mathrm{m}$ size. RMS roughness was determined to be less than about $1.5 \mathrm{~nm}$ by FIB cross-section. Indeed, no roughness could be distinguished in images resulting from such cross-sections, meaning that if such a roughness exists, it is lower than the detection limit of the instrument. After polishing, the samples were rinsed with acetone, ethanol and isopropanol. The samples were then treated in a Fischione model 1020 plasma cleaner for $15 \mathrm{~min}$. The $\mathrm{Ar}: \mathrm{O}_{2}$ ratio of the plasma is 3:1. Although no time dependence was found after 30 seconds of plasma treatment[24], the 
plasma was held for 15 min to remove any layer resulting from surface damage during the mechanical polishing step. This was verified in 2 ways : (i) the thermal conductivities of all the diamond substrates were verified to be above $1000 \mathrm{Wm}^{-1} \mathrm{~K}^{-1}$, the value expected for the type of diamond used and the spot size used in the TDTR experiment[24], (ii) no defects were found in the diamond substrate when performing cross-sectional high resolution electron microscopy on the samples used for STEM-EDX. The samples were then transferred to a Balzers BAS 450 Sputter deposition system and received a layer of $\mathrm{Cr}, \mathrm{Mo}, \mathrm{Nb}$ or $\mathrm{W}$ according to the parameters listed in Table 1 . The sputtering gas is Ar, at a pressure of $5.2 \times 10^{-3}$ mbar, and the power of the magnetron depends on the metal, ranging from 500 to $2000 \mathrm{~W}$. Prior to the deposition process, the targets were cleaned for about 5 min in order to make sure that as little surface oxide from the target as possible was included in the resulting layer. Layer deposition rates were calculated by dividing the layer thickness (measured ex situ by cross section imaging using a Zeiss NVision 500 Focused Ion Beam) by the deposition time.

The TBC between the layers and the substrate was measured by TDTR des-

TABLE 1: Deposition parameters of the metal layers deposited.

\begin{tabular}{|c|c|c|}
\hline $\begin{array}{c}\text { Layer } \\
\text { metal }\end{array}$ & $\begin{array}{c}\text { Deposition } \\
\text { rate }\left[\AA^{-1}\right]\end{array}$ & $\begin{array}{c}\text { thickness } \\
{[\mathrm{nm}]}\end{array}$ \\
\hline $\mathrm{Cr}$ & 6 & $97 \pm 2$ \\
$\mathrm{Nb}$ & 4.5 & $112 \pm 2$ \\
$\mathrm{Mo}$ & 7.9 & $95 \pm 3$ \\
$\mathrm{~W}$ & 3.2 & $106 \pm 3$ \\
\hline $\mathrm{Al}$ & 6.0 & $78 \pm 2$ \\
\hline
\end{tabular}

cribed in detail below. The samples were then loaded in an in-house vacuum annealing setup available at the Laboratory of Ceramics, EPFL, in which they were heat treated at $800{ }^{\circ} \mathrm{C}$ for $2 \mathrm{~h}$, with a $10 \mathrm{Kmin}^{-1}$ heat up speed and a cool down time of $4 \mathrm{~h}$ in a vacuum of $10^{-7}$ mbar or better.

To study the early stages of the layer deposition, ultra thin (below $2 \mathrm{~nm}$ ) layers of Mo and Cr were deposited on diamond substrates for XPS investigation. XPS data were collected by an Axis Ultra (Kratos analytical, Manchester, UK) under ultra-high vacuum condition $\left(<10^{-8} \mathrm{mbar}\right)$, using a monochromatic $\mathrm{Al} \mathrm{K} \alpha$ X-ray source $(1486.6 \mathrm{eV})$. The source power was 
maintained at $150 \mathrm{~W}(10 \mathrm{~mA}, 15 \mathrm{kV})$. The emitted photoelectrons were sampled from a rectangular area of 750 by $350 \mu \mathrm{m}$. Gold $\left(\mathrm{Au} \mathrm{4} 4_{f}^{7 / 2}\right.$ ) and copper $\left(\mathrm{Cu} 2_{p}^{3 / 2}\right)$ lines at 84.0 and $932.6 \mathrm{eV}$, respectively, were used for calibration. Target layer thicknesses of $1 \mathrm{~nm}$ were set, though due to the fact that the layer is in its nucleation stage at this point, the exact thickness of the layer and its surface coverage cannot be known with precision[27].

\subsection{Chemical characterization}

Prior to heat treatment, TEM lamellae were extracted from each sample using the FIB microscope mentioned above. The layers were verified to be metallic using a FEI Tecnai Osiris microscope operated in Scanning Transmission Electron Microscopy (STEM) Energy Dispersive X-ray spectroscopy (EDX) mode at $200 \mathrm{kV}$. After the heat treatment, a new TEM lamella was extracted and EDX maps were acquired on each layer. The tungsten layer did not exhibit any reaction with the diamond substrate (less than 5 at.\% carbon was found in the bulk of the layer) and thus was transferred to a FEI CM300 microscope (operated at $300 \mathrm{kV}$ ) for Selected Area Diffraction (SAD) experiments.

When investigating the $\mathrm{Nb}$ layer after heat treatment, it quickly disappeared upon shining by the electron beam in TEM. Therefore, as an alternative, XPS was performed at its surface, following various times of a light sputtering using Ar ions at $0.5 \mathrm{keV}$ to rid the surface of its native oxide as well as its contaminants. Prior to sputtering, the adventitious carbon peak was calibrated at $284.5 \mathrm{eV}[28]$ to make sure the recorded results could be compared with literature values.

\subsection{Time Domain ThermoReflectance (TDTR)}

The experimental setup used for the TDTR experiments is a coaxial twotints pump/probe experiment[22]. This setup uses a Spectra Physics tsunami laser generating pulses of about 200 fs at a repetition rate of $80 \mathrm{MHz}$ and $790 \mathrm{~nm}$ wavelength. Its beam is split into two parts, the pump (which heats the sample's surface) and the probe (which measures the reflectivity of the sample's metallic surface, which is proportional to its temperature[29, 30]). The pump beam passes through a sharp longpass filter set a $790 \mathrm{~nm}$ and the probe passes through a shortpass filter set at $780 \mathrm{~nm}$. Both pump and probe are focused on the same spot on the sample's surface. The pump's optical 
path length can be varied mechanically, thereby enabling the creation of a delay between arrivals of the pump and probe on the sample surface from 0 to $4 \mathrm{~ns}$. The pump beam is modulated at a frequency of $10.7 \mathrm{MHz}$ using an electro-optic modulator.

After being reflected by the sample and passed through a second shortpass filter set at $780 \mathrm{~nm}$ to improve the signal-to-noise ratio by eliminating possible stray light from the pump, the probe signal is monitored using a 1 ns rise time photodiode. The resulting signal is passed through a band-pass electronic filter at $10.7 \mathrm{MHz}$, amplified, and fed to a Zurich Instrument Hf2Li lock-in amplifier. The $\mathrm{X} / \mathrm{Y}$ ratio (where $\mathrm{X}$ is the in-phase and $\mathrm{Y}$ the out-of-phase signal of the lock-in amplifier) of the values measured by the lock-in was used for data extraction, as this strongly limits the impact of a change in the overlap of the two spots due to mechanical beam steering[31]. Spots of about $5 \mu \mathrm{m} e^{-2}$ radius for both pump and probe are used, achieving fluences between 0.6 and $2.0 \mathrm{mJcm}^{-2}$ depending on the metal investigated, leading to temperature rises of less than $3 \mathrm{~K}$. Beam steering of the pump is monitored using a CMOS camera in the beamline as described in [22] and is kept under $2 \mu \mathrm{m}$ over the full range of time delays. The same camera is used to measure the spot size at the beginning and the end of the delay stage. We use the model given by Cahill[31, 32] to extract the values of TBC through a fit of the experimental data. The main fitting parameter is the TBC; however, presumably due to small variation in the diamonds' nitrogen content[33], the diamond substrate conductivity must also be varied somewhat to obtain a good fit to experimental data.

The TDTR measurements were performed before and after heat treatment. Before heat treatment, a clear signal was obtained on all metals, as could be expected from their reasonably high thermoreflectance coefficient[34]. After heat treatment, the $\mathrm{W}$ and Mo layers could be investigated similarly, since the top surface was found to be still metallic. For the Cr and Nb surfaces, only a weak signal was recorded and the data quality was insufficient to permit an adequate fit of the recorded curves. Thus, the samples were put in a Balzers BAS450 sputter deposition system. The native oxide at the surface of the samples was removed by etching the surface using the deposition system in radiofrequency Ar plasma etch at $500 \mathrm{~W}$ for $2 \mathrm{~min}$. A $78 \mathrm{~nm}$ Al layer was subsequently deposited at a speed of $6.0 \AA^{-1}$ and a pressure of $4.3 \cdot 10^{-3} \mathrm{mbar}$. Layer thicknesses were re-verified afterwards by FIB cross-section imaging to account for the material removed by the etching as well as the exact $\mathrm{Al}$ layer thickness. TDTR measurements were then performed, leading to curves 
suitable for TBC extraction.

\section{Results}

\subsection{Transmission Electron Microscopy (TEM)}

Figure 1 shows EDX linescans recorded through (a) the pristine Mo layer and (b-d) the heat treated layers of $\mathrm{Cr}$, Mo and W (NbC layers were heavily damaged by the electron beam and no reliable measurement could be obtained). Other linescans from untreated layers are not shown but exhibit 5 at\% or less C upon elemental analysis. The linescans are extracted from a map recorded over the whole image shown, using areas of interest $140 \mathrm{~nm}$ in length and summing the contributions from points recorded on a strip of $40 \mathrm{~nm}$ width to improve the signal-to-noise ratio. Special care was taken to position the lines at exactly $90^{\circ}$ to preserve the sharpness of interfaces. As EDX is sensitive to mass, and as the mass contrast between the metals investigated and carbon is very high, the estimated uncertainty on the graphs is 5 at $\%$.

Figure 2 shows two examples of diffraction patterns obtained by selecting the tungsten layer of the $\mathrm{W}$ on diamond samples heat treated at $800^{\circ} \mathrm{C}$ for 2 $\mathrm{h}$, using the area selecting aperture of a FEI CM300 microscope. Sampling of the layer only was verified by defocussing the diffraction pattern until the image appeared in the diffraction spots. It was then made sure that the substrate did not appear in these spots before putting the pattern back into focus. White circles indicate reciprocal distances related to metallic tungsten and tungsten oxide (taken from Ref. [35]). Dashed white circles indicate reciprocal distances related to tungsten carbides, $\mathrm{W}_{2} \mathrm{C}$ or $\mathrm{WC}$ (taken from Refs. [35, 36]).

\subsection{X-ray Photoelectron Spectroscopy (XPS)}

\subsubsection{Heat-treated niobium layer composition}

Figure 3 shows the results obtained from the XPS experiments on the $\mathrm{Nb}$ over diamond layer heat treated at $800^{\circ} \mathrm{C}$ for $2 \mathrm{~h}$.

Table 2 shows measured subpeak positions for the spectra recorded around the $\mathrm{Nb}_{d}^{3}, \mathrm{C}_{s}^{1}$ and $\mathrm{O}_{s}^{1}$ energies, and corresponding literature data.

\subsubsection{Ultrathin films of $\mathrm{Cr}$ and $\mathrm{Mo}$}

XPS investigation of the surfaces after deposition revealed a weak $\mathrm{Cr}_{s}^{2}$ peak in addition to the $\mathrm{O}_{s}^{1}$ and $\mathrm{C}_{s}^{1}$ on the surface with ultrathin $\mathrm{Cr}$, and strong 
TABLE 2: Subpeak positions for the spectra recorded around the $\mathrm{Nb}_{d}^{3}, \mathrm{C}_{s}^{1}$ and $\mathrm{O}_{s}^{1}$ energies on the heat treated $\mathrm{Nb}$ on diamond sample after $18 \mathrm{~min}$ of Ar sputtering, compared to literature data.

\begin{tabular}{|l|c|c|c|}
\hline Peak type & \multicolumn{2}{|c|}{ Peak position [eV] } & Reference \\
& Experiment & literature & \\
\hline $\mathrm{C}_{s}^{1}$, adv. & 284.3 & 284.5 & {$[28]$} \\
$\mathrm{C}_{s}^{1}, \mathrm{C}-\mathrm{O}$ & 286.2 & 286.2 & {$[37,38]$} \\
$\mathrm{C}_{s}^{1}, \mathrm{NbC}$ & 281.9 & 282.1 & {$[39]$} \\
$\mathrm{Nb}_{3 d}^{5 / 2}, \mathrm{Nb}_{2} \mathrm{O}_{5}$ & 207.3 & 206.9 & {$[40]$} \\
$\mathrm{Nb}_{3 d}^{3 / 2}, \mathrm{Nb}_{2} \mathrm{O}_{5}$ & 210.1 & 208.8 & {$[40]$} \\
$\mathrm{Nb}_{3 d}^{5 / 2}, \mathrm{NbC}^{3 / 2}, \mathrm{NbC}$ & 202.7 & 202.7 & {$[41]$} \\
$\mathrm{Nb}_{3 d}^{3 / 2}, \mathrm{NbC}$ & 205.4 & 205.4 & {$[41]$} \\
$\mathrm{O}_{s}^{1}, \mathrm{adv}^{1}$ & 531.4 & 531.4 & {$[28]$} \\
$\mathrm{O}_{s}^{1}, \mathrm{Nb}_{2} \mathrm{O}_{5}$ & 530.3 & 530.4 & {$[42]$} \\
\hline
\end{tabular}

$\mathrm{Mo}_{s}^{3}, \mathrm{Mo}_{p}^{3}$, and $\mathrm{Mo}_{d}^{3}$ signals on the surface with ultrathin Mo. The signal to noise ratio was not good enough with $\mathrm{Cr}$ to extract data for either the $\mathrm{Cr}_{s}^{2}$ or $\mathrm{Cr}_{p}^{2}$ peaks, while Mo oxides and carbides are hard to distinguish from each other[43-45]. Consequently, only the $\mathrm{C}_{s}^{1}$ peak could be used efficiently for analysis purpose, and it is shown in Figure 4.

\subsection{Time domain thermoreflectance}

Figure 5 shows examples of the acquired TDTR curves before and after heat treatment, with corresponding measured TBCs, for a system where an $\mathrm{Al}$ layer was deposited after heat treatment $(\mathrm{Cr} / \mathrm{C})$ and a system where such a layer was unnecessary $(\mathrm{Mo} / \mathrm{C})$. Table 3 shows the TBC between layer and substrate measured before and after high vacuum heat treatment at $800^{\circ} \mathrm{C}$ for $2 \mathrm{~h}$. The layer compositions and thicknesses deduced from Figures 1, 2 and 3 are indicated. The thermophysical properties of the carbides are taken from Reference [46], except for $\mathrm{Mo}_{2} \mathrm{C}$, where no data could be obtained at ambient temperature. In this case, a Debye heat capacity of $2.8 \mathrm{MJm}^{-3} \mathrm{~K}^{-1}$ was calculated, using the Debye temperature and sound velocities provided in Reference [47]. The standard deviation obtained over 4 measurements gives an assessment of the repeatability of the measurements, but an additional error of $10 \%$ due to uncertainties in thermophysical properties, layer thickness, 
TABLE 3: Measured TBC of the samples investigated before and after high vacuum heat treatment at $800^{\circ} \mathrm{C}$ for $2 \mathrm{~h}$. The errors mentioned in the $\mathrm{TBC}$ values are the standard deviation over 4 measurements.

\begin{tabular}{|c|c|c|c|}
\hline \multicolumn{2}{|l|}{ Layer composition } & \multicolumn{2}{c|}{ TBC $\left[\mathrm{MWm}^{-2} \mathrm{~K}^{-1}\right]$} \\
Before HT & after HT & Before HT & after HT \\
\hline Nb, 112 nm & Al $78 \mathrm{~nm}, \mathrm{NbC} 134 \mathrm{~nm}$ & $220 \pm 10$ & $230 \pm 10$ \\
Mo $95 \mathrm{~nm}$ & Mo $21 \mathrm{~nm}, \mathrm{Mo}_{2} \mathrm{C} 78 \mathrm{~nm}$ & $220 \pm 10$ & $240 \pm 10$ \\
Cr $97 \mathrm{~nm}$ & $\mathrm{Al} 78 \mathrm{~nm}, \mathrm{Cr}_{3} \mathrm{C}_{2} 115 \mathrm{~nm}$ & $315 \pm 15$ & $320 \pm 40$ \\
W $106 \mathrm{~nm}$ & W $105 \mathrm{~nm}$ & $205 \pm 10$ & $200 \pm 10$ \\
\hline
\end{tabular}

and laser spot radius measurement are to be expected.

\section{Discussion}

\subsection{Compositions of the layers}

The EDX linescans in Figure 1 suggest that, prior to heat treatment, the layers are essentially metallic as shown in part (a) of the Figure. The same conclusion was reached for the other metal layers as their elemental quantification revealed less the 5 at\% C. Figures 1 (b) and (c) show that molybdenum and chromium carbides have formed upon heat treatment. In the case of Mo (Figure $1 \mathrm{~b}$ ), where the layer seems to have reacted to consume only a part of the metal layer's thickness, the Mo/C ratio suggests a composition close to the stable phase $\mathrm{Mo}_{2} \mathrm{C}$ in the interfacial layer, with pure Mo remaining in the top layer. Indeed, there are only two stable Mo carbides : $\mathrm{Mo}_{2} \mathrm{C}$ and $\mathrm{MoC}$ and here the ratio between $\mathrm{Mo}$ and $\mathrm{C}$ concentrations is clearly closer to 2:1. The $\mathrm{Cr}$ layer (Figure 1c) has completely reacted, and the $\mathrm{Cr} / \mathrm{C}$ ratio suggests a composition close to the stable phase $\mathrm{Cr}_{3} \mathrm{C}_{2}$. Smearing of the $\mathrm{W}$ and $\mathrm{C}$ concentrations over $20 \mathrm{~nm}$ at the $\mathrm{W} /$ diamond interface (Figure $1 \mathrm{~d}$ ), as well as the presence of weak spots from $\mathrm{WC}$ and $\mathrm{W}_{2} \mathrm{C}$ in the diffraction patterns (Figure 2), suggest that carbide has probably formed at the interface, though with a very limited thickness. This limited carbide formation is probably due to a very low diffusion coefficient of carbon across WC. Extrapolating data for the diffusion coefficient of $\mathrm{C}$ in $\mathrm{W}_{2} \mathrm{C}$ from Ref. [48] yields a value of $10^{-15} \mathrm{~cm}^{2} \mathrm{~s}^{-1}$, which would mean a layer of $27 \mathrm{~nm}$ in $2 \mathrm{~h}$. This suggests that the diffusion coefficient of carbon in $\mathrm{WC}$ is even lower, as the 
interface smearing between $\mathrm{W}$ and $\mathrm{C}$ on Figure $1 \mathrm{~d}$ ) is below $20 \mathrm{~nm}$. Thickness measurement at a nm scale would be hazardous as a slight tilt of the sample surface with respect to the [100] direction would change the result obtained. However the uncertainty in thickness has only a limited impact on the thermal model used to extract TBC values as the heat capacity of WC at ambient is $2.84 \mathrm{MJm}^{-3} \mathrm{~K}^{-1}$, which is only $11 \%$ higher than that of pure $\mathrm{W}$. Hence the calculation of TBC using the heat capacity of $\mathrm{W}$ for the whole layer should be a good approximation.

Binding energies measured by XPS investigation of the $\mathrm{Nb}$ /diamond sample after heat treatment (Table 2, Figure 3) match very closely the values found for $\mathrm{Nb}_{2} \mathrm{O}_{5}$ and $\mathrm{NbC}$ in the literature. This clearly indicates that a carbide has formed throughout the whole layer except where an oxide was previously present at its surface, as suggested by the shift in the $\mathrm{C}_{s}^{1}$ towards the carbide peak upon Ar sputtering, observed in Figure 3 (a) and (b).

\subsection{XPS on ultra thin films of $\mathrm{Cr}$ and $\mathrm{Mo}$}

The XPS signal around the main diamond $\mathrm{sp}^{3}$ carbon peak at $285.5 \mathrm{eV}$ exhibits small subpeaks at energies below $284 \mathrm{eV}$, i.e. the $\mathrm{sp}^{2}$ carbon subpeak. For the sake of comparison, the signal is normalized to its peak value at $285.5 \mathrm{eV}$. This normalization, along with the difference in atomic weights between Mo and $\mathrm{Cr}$ and the difference in layer thicknesses, explains the fact that the subpeaks do not have the same magnitude from sample to sample. For Cr ultrathin film, the closest corresponding literature reference to the peak found at $281.5 \mathrm{eV}$ in the present data is that of $\mathrm{Cr}_{3} \mathrm{C}_{2}$ at 282.5[49]. For the ultra-thin Mo layer the subpeak found at $283.3 \mathrm{eV}$ is taken to correspond to a $\mathrm{Mo}_{2} \mathrm{C}$ peak at $282.7 \mathrm{eV}[39]$. The observed energy values do not correspond exactly to the cited reference peaks, but subpeaks observed below the main diamond peak cannot be attributed to other species often observed on a diamond surface, i.e. hydrogen[50-53] or oxygen[37, 38], since these species are known to shift the binding energy towards higher values[37, 38, 50, 51]. On the other hand, bonding with transition metals produces peaks at $l o-$ wer energies than the $\mathrm{sp}^{3}$ peak of carbon e.g. for $\mathrm{Cr}[49], \mathrm{Mo}[39], \mathrm{Nb}[39]$ or $\mathrm{W}[54,55]$, suggesting that the observed subpeaks can be attributed to the respective metal carbides. Moreover, the measurements are made on sub-nmsized layers, i.e. not bulk material, which may also slightly change the binding energy. We therefore conclude that the deposition of $\mathrm{Cr}$ and Mo starts with the formation of a carbide or carbide-like layer at the substrate/layer interface. By extension, since $\mathrm{Nb}$ and $\mathrm{W}$ are also strong carbide formers, we infer 
by analogy that this is the case for every sample investigated in this study.

\subsection{Thermal boundary conductance between metals and their carbides and diamond}

TBCs reported in Table 3 are identical before and after heat-treatment within their standard deviation for all materials except Mo. As noted before, an additional error of $10 \%$ due to the experimental technique is to be expected and thus even for Mo the values would correspond within error. Moreover, the volumetric heat capacity of $\mathrm{Mo}_{2} \mathrm{C}$ was deduced from its elastic constants[47] since, to the authors' best knowledge, no direct measurements at ambient are available in the literature. Even though the obtained heat capacity curve yielded values very close to experimentally measured ones at higher temperatures, this may account for the $20 \mathrm{MWm}^{-2} \mathrm{~K}^{-1}$ difference between values before and after heat treatment.

Besides, according to widespread analytical models describing TBC quantitatively, such as the Acoustic[68] or Diffuse[64] Mismatch Model (AMM and DMM, respectively), a change in the nature of the materials composing the interface, especially in their phonon spectrum, should directly impact TBC. Indeed, the general formulation describing $h_{b d}$, the TBC, is :

$h_{b d}=\frac{1}{2} \sum_{p} \int_{0}^{\frac{\pi}{2}} \int_{0}^{\omega_{\max }} \hbar \omega v_{p}(\omega) \frac{\partial n(\omega, p, T)}{\partial T} D O S(\omega) \alpha_{1 \rightarrow 2}(\theta, p, \omega) \cos \theta \sin \theta d \theta d \omega$

with $p$ the phonon polarization, $v$ the phonon velocity, $\omega$ its pulsation, with a maximum value $\omega_{\max }$, typically imposed by the metal for metal/diamond interface. $n$ is the Bose occupation factor and $\alpha_{1 \rightarrow 2}$ an interfacial transmission coefficient, usually containing the central hypotheses of the elastic scattering model such as AMM or DMM. DOS $(\omega)$ is the phonon density of states of the material. If Eqn. 1 is taken to its limit, assuming no inelastic phonon scattering, which is called the phonon Radiation Limit (RL) [64, 65], the contribution from phase velocities of the upper layers are no longer important, leaving $\omega_{\max }$ as the crucial parameter allowing for a quantitative assessment of TBC. A good measurement of $\omega_{\max }$ of a material is provided by its Debye temperature $\Theta_{D}[66]$, and thus a change in $\Theta_{D}$ upon the layer's transformation into carbide should be a reliable indicator that Equation 1 applies.

Table 4 shows literature values of the Debye temperatures of the materials investigated $\left(\Theta_{D}\right.$ of diamond is of $\left.2240 \mathrm{~K}[65]\right)$, as well as the experiments from 
TABle 4: Debye temperatures of $\mathrm{Cr}, \mathrm{Mo}, \mathrm{Nb}$ and $\mathrm{W}$ and their respective carbides. The physical quantities from which $\Theta_{D}$ is deduced are mentioned as they may not yield identical $\Theta_{D}$ values. RT means room temperature, LT low temperature.

\begin{tabular}{|l|c|l|}
\hline Material & $\Theta_{D}[\mathrm{~K}]$ & Ref. \\
\hline $\mathrm{Cr}$ & $598,512,602$ & LT heat capacity, [56, 57], RT Elastic constants [57] \\
$\mathrm{Cr}_{3} \mathrm{C}_{2}$ & 470 & LT heat capacity, [58] \\
$\mathrm{Nb}$ & 277 & LT heat capacity [56] \\
$\mathrm{NbC}$ & 740,377 & RT elastic properties [59], RT heat capacity [60] \\
$\mathrm{Mo}$ & 470 & LT heat capacity[56] \\
$\mathrm{Mo} 2 \mathrm{C}$ & 490 & RT elastic properties [47] \\
$\mathrm{W}$ & 380,304 & LT heat capacity [56], First principles [61] \\
$\mathrm{WC}$ & $621,648,590$ & RT heat capacity[62], First principles [61, 63] \\
$\mathrm{W}_{2} \mathrm{C}$ & 425,450 & First principles [61, 63] \\
\hline
\end{tabular}

which they have been deduced (as this can substantially change the result [66]). It suggests that differences should appear at least in the $\mathrm{Nb} /$ diamond case, where the Debye temperature of the carbide is at least $33 \%$ higher than that of the metal. Differences should also be visible in $\mathrm{Cr} /$ diamond couple as the Debye temperature of the carbide is at between 8 and $22 \%$ lower than the metal's. For the $\mathrm{W} /$ diamond couple, the formation of $\mathrm{W}_{2} \mathrm{C}$ and $\mathrm{WC}$ at the interface, as suggested by Figures 1 and 2, means that a change can be expected, as interfacial layers are known to have an influence on TBC[17, 67] down to $\mathrm{nm}$ size. The Mo/C system is the only one where no change should occur if the Debye temperatures of the metal and its carbides are considered. In view of what proceeds it is surprising that the heat treatment does not seem to lead to a significant change in TBC in any of the systems investigated here, despite the clear evidence that the phases forming the interface do change during the heat treatment. On the other hand, the nature of the metal carbon bonds at the interface is already carbide-like after deposition as shown by the XPS results (see Fig. 4). Hence it would seem that these carbide-like bonds control the conductance of an interface, not only the bulk properties of the phases on each side of it. Whether it is the bond strength alone or a consequence of potential phonon states associated with the transition in bond strength in the interfacial region cannot be conclusively answered 
by this investigation. However, depositing Cr directly on an in situ RFetched-diamond surface, instead of ex situ Ar :O plasma treated diamonds as conveyed above, yields a TBC of $450 \pm 50 \mathrm{MWm}^{-2} \mathrm{~K}^{-1}$, suggesting that the quality of the very interface at its formation is crucial (i.e. the diamond surface prior to the metal deposition), rather than a transition layer that a priori should be the same for the two deposition conditions investigated. In order to transpose the observations reported here to composites it would be interesting to study in situ-formed interfaces during composite processing by dissolving the matrix of a MMC and observe the obtained diamond particles in a similar way as in Ref.[12]. This approach would furthermore allow for the measurement of the conductivity of the carbide itself and the interface conductance by TDTR as a function of processing parameters, the former also being a factor that can limit the thermal conductivity of a MMC.

\section{Conclusion}

Samples consisting in thin films of $\mathrm{Cr}, \mathrm{Nb}$, Mo and $\mathrm{W}$ layers on diamond were prepared by sputter deposition. The Thermal Boundary Conductance at the resulting metal/diamond interfaces was measured by Time Domain ThermoReflectance prior to and after a heat treatment in high vacuum at $800^{\circ} \mathrm{C}$ for $2 \mathrm{~h}$. While only interfacial (i.e. of thickness not measurable precisely using DFSTEM) carbides formed upon heat treatment in the case of $\mathrm{W}$, quasi-complete (for $\mathrm{Mo}$ ) and complete transformation of the layer into carbides was respectively observed in the case of $\mathrm{Mo}, \mathrm{Nb}$ and $\mathrm{Cr}$. The phases formed were $\mathrm{WC}, \mathrm{W}_{2} \mathrm{C}, \mathrm{Mo}_{2} \mathrm{C}, \mathrm{NbC}$ and $\mathrm{Cr}_{3} \mathrm{C}_{2}$.

No significant difference in $\mathrm{TBC}$ between the metal/diamond and the carbide/diamond cases was observed, suggesting that TBC is strongly affected by interfacial carbides that have formed at the metal/diamond interface already during metal deposition, not only by the phononic spectra of the bulk of the layer.

Heat treatment does not improve the thermal transfer between metal and diamond, even if that metal can form carbides. This has direct implications in the design of diamond-based MMCs, as the technique used to put metal and diamond into contact should ensure a high quality interface during the early stages of the composite production process. 


\section{Acknowledgments}

Financial support of C. Monachon by the SNSF Project No. 200021121881 and 200020-135132 is gratefully acknowledged. The authors kindly acknowledge Paul Muralt, Monika Iwanowska and Mahamudu Mtebwa from the Laboratory of Ceramics, EPFL, for their help in the high vacuum heat treatments. Marco Cantoni from the CIME, EPFL is warmly acknowledged for his patient help with TEM lamellae preparation and investigations. Nicolas Xanthopoulos is acknowledged for the XPS measurement performed at the CIME, EPFL. Finally, Professor Hubert Girault of the Laboratoire d'Électrochimie Physique et Analytique (LEPA) at EPFL is acknowledged for providing the laser source for the experiments. Prof David G. Cahill of the University of Illinois at Urbana Champaign is gratefully acknowledged for his helpful pieces of advice.

[1] C. Zweben, J Adv. Mater. 39 (2007) 3-10.

[2] R. Tavangar, L. Weber, Emerg. Mater. Res. 1 (2012) 67-74.

[3] P. W. Ruch, O. Beffort, S. Kleiner, L. Weber, P. J. Uggowitzer, Compos. Sci. Technol. 66 (2006) 2677-2685.

[4] O. Beffort, F. A. Khalid, L. Weber, P. Ruch, U. E. Klotz, S. Meier, S. Kleiner, Diam. Relat. Mater. 15 (2006) 1250-1260.

[5] J. M. Molina, M. Rhême, J. Carron, L. Weber, Scripta Mater. 58 (2008) 393-396.

[6] L. Weber, R. Tavangar, Scripta Mater. 57 (2007) 988-991.

[7] M. Kida, L. Weber, C. Monachon and A. Mortensen, J. Appl. Phys. 109 (2011), 064907 1-9.

[8] I. E. Monje, E. Louis, J. M. Molina, Compos Part A-Appl S 48 (2013) $9-14$.

[9] J.-F. Silvain, A. Veillere, J.-M. Heintz, C. Vincent, T. Guillemet, G. Lacombe, Y. Lu, N. Chandra, Emerg. Mater. Res. 1 (2012) 75-87.

[10] T. Schubert, L. Ciupinski, W. Zielinski, A. Michalski, T. Weissgärber, B. Kieback, Scripta Mater. 58 (2008) 263-266. 
[11] K. Chu, C. Jia, H. Guo, W. Li, Mater Design 45 (2013) 36-42.

[12] T. Schubert, B. Trinidade, T. Weissgärber, B. Kieback, Mat. Sci. Eng. A 475 (2008) 39-44.

[13] J. Hell, M. Horkel, E. Neubauer, C. Eisenmenger-Sittner, Vacuum 84 (2010) 453-457.

[14] Q. Kand, X. He, S. Ren, L. Zhang, M. Wu, C. Guo, Q. Liu, T. Liu and X. Qu, J. Alloy Compd. 576 (2013) 380-385.

[15] Q. Kand, X. He, S. Ren, L. Zhang, M. Wu, C. Guo, W. Cui and X. Qu, Appl. Therm. Eng. 60 (2013) 423-429.

[16] A. M. Abyzov, S. V. Kidalov, F. M. Shakhov, J. Mater. Sci. 46 (2011) 1424-1438.

[17] M. D. Losego, M. E. Grady, N. R. Sottos, D. G. Cahill, and P. V. Braun, Nature Mater. Lett. 11 (2012) 502-505.

[18] C. Monachon, G. Schusteritsch, E. Kaxiras, L. Weber, J. Appl. Phys. 115 (2014) 123509 1-7.

[19] T. S. English, J. C. Duda, J. L. Smoyer, D. A. Jordan, P. M. Norris, and L. V.Zhigilei, Phys. Rev. B 85 (2012) 035438 1-14.

[20] C. B. Saltonstall, C. A. Polanco, J. C. Duda, A. W. Ghosh, P. M. Norris, and P. E. Hopkins, J. Appl. Phys. 113 (2013) 013516 1-8.

[21] C. A. Paddock, G. L. Eesley, J. Appl. Phys. 60 (1986) 285- 290.

[22] K. Kang, Y. K. Koh, C. Chiritescu, X. Zheng, D. G. Cahill, Rev. Sci. Instr. 79 (2008) 114901 1-4.

[23] K. C. Collins, S. Chen, G. Chen, Appl. Phys. Lett. 97, 083102 (2010) $1-3$.

[24] C. Monachon, L. Weber, J. Appl. Phys. 113, 183504 (2013) 1-8.

[25] C. Monachon, L. Weber, Diam. Relat. Mater. 39 (2013) 8-15.

[26] C. Monachon, L. Weber, Emerg. Mater. Res. 1 (2012) 89-98. 
[27] C. T. Campbell, Surf. Sci. Rep. 27 (1997) 1-111.

[28] J. F. Moulder, W. F. Stickle, P. E. Sobol, K. D. Bomben, Handbook of X-Ray Photoelectron Spectroscopy, Perkin-Elmer Corporation,Physical Electronics Division, Eden Prairie, Minnesota 55344, 1979.

[29] K. Ujihara, J. Appl. Phys. 43 (1971) 2376-2383.

[30] R. B. Wilson, B. A. Apgar, L. W. Martin, D. G. Cahill, Opt Express 20 (2013) $1-10$.

[31] R. M. Costescu, M. D. Wall, D. G. Cahill, Phys. Rev. B 67 (2003) 054302 $1-5$.

[32] D. G. Cahill, Rev. Sci. Instr. 75 (2004) 5119-5122.

[33] Y. Yamamoto, T. Imai, K. Tanabe, T. Tsuno, Y. Kumazawa, N. Fujimori, Diam. Relat. Mater. 6 (1997) 1057-1061.

[34] Y. Wang, J. Y. Park, Y. K. Koh, D. G. Cahill, J. Appl. Phys. 108 (2010) 043507 1-4.

[35] R. W. G. Wyckoff, The second edition of Structure of Crystals, The Chemical Catalog Company, INC, New York, 2 edition, 1931.

[36] J. Leciejewicz, Acta Crystall. 14 (1961) 200-201.

[37] P. Mérel, M. Tabbal, M. Chaker, S. Moisa, J. Margot, Appl. Surf. Sci. 136 (1998) 105-110.

[38] J. J. B. Wilson, J. S. Walton, G. Beamson, J. Electron Spectrosc. 121 (2001) 183-201.

[39] L. Ramqvist, K. Hamrin, G. Hohansson, A. Fahlman, C. Nordling, J. Phys. Chem. Sol. 30 (1969) 1835-1847.

[40] N. Oezer, M. D. Rubin, C. M. Lampert, Sol Energ Mat Sol C 40 (1996) 285-296.

[41] V. Texeira da Silva, M. Schmal, S. Oyama, J. Solid State Chem. 123 (1996) 168-182. 
[42] S. F. Ho, S. Contarini, J. W. Rabelais, J. Phys. Chem. 91 (1987) 47794788.

[43] H.-M. Wu, S.-A. Chen, Synthetic Met. 26 (1988) 225-236.

[44] S. O. Grim, L. J. Matienzo, Inorg. Chem. 14 (1975) 1014-1018.

[45] L. Leclercq, M. Provost, H. Pastor, J. Grimblot, A. Hardy, L. Gengembre, G. Leclercq, J. Catal. 17 (1989) 371-383.

[46] H. O. Pierson, Handbook of refractory carbides and nitrides, Noyes Publications, Westwood, 1996.

[47] M. Cankurtaran, S. P. Dodd, B. James, J. Mater. Sci. 39 (2004) 1241-1248.

[48] S. L. Kharatyan, H. A. Chatilyan, L. H. Arakelyan, Mater. Res. Bull. 43 (2008) 897-906.

[49] H. Goretzki, P. Rosenstiel, S. Mandziej, Fresen. Z. fuer Anal. Chem. 333 (1989) 451-452.

[50] L. Diederich, O. M. Kuettel, P. Ruffieux,T. Pillo, P. Aebi, L. Schlapbach, Surf. Sci. 417 (1998) 41-52.

[51] L. Diederich, O. M. Kuettel, P. Aebi, L. Schlapbach, Surf. Sci. 418 (1998) 219-239.

[52] R. Graupner, J. Ristein, L. Ley, Surf. Sci. 320 (1994) 201-207.

[53] G. Francz, P. Kania, G. Gantner, H. Stupp, P. Oelhafen, Phys. Status Solidi A 154 (1996) 91-108.

[54] R. J. Colton, J. W. Rabalais, Inorg. Chem. 15 (1976) 237-239.

[55] A. Katrib, H. P. Wehrer, L. Hilaire, G. Maire, J. Electron Spectrosc. 76 (1995) 195-200.

[56] A. Ferndandez Guillermet, G. Grimvall, Phys. Rev. B 40 (1989) $1521-1527$.

[57] R. H. Wilson, E. F. Skelton, L. J. Katz, Acta Crystall. 21 (1966) 635-639. 
[58] W. DeSorbo, J. Am. Chem. Soc. 75 (1953) 1825- 1827.

[59] C. K. Jun, T. B. Shaffer, J. Less-Common Met. 23 (1971) 367-373.

[60] A. I. Gusev, A. A. Rempel, V. N. Lipatnikov, Phys. Status Solidi B 194 (1996) 467-482.

[61] V. P. Zhukov, V. A. Gubanov, Solid State Commun. 56 (1985) 51-55.

[62] R. R. Reeber, K. Wang, J. Am. Ceram. Soc. 82 (1999) 129-135.

[63] Y. Li, Y. Gao, B. Xiao, T. Min, Z. Fan, S. Ma, L. Xu, J. Alloy Compd. $502(2010) 28-37$.

[64] E. T. Swartz, R. O. Pohl, Rev. Mod. Phys. 61 (1989) 605- 668.

[65] R. J. Stoner, H. J. Maris, Phys. Rev. B 48 (1993) 16373-16387.

[66] C. Kittel, Introduction to Solid State Physics, John Wiley and Sons, Inc, 8 edition, 2005.

[67] J. C. Duda, Y. C.-Y. P., B. M. Foley, R. Cheaito, D. L. Medlin, R. E. Jones, P. E. Hopkins, Appl. Phys. Lett. 102 (2013) 081902 1-3.

[68] W. A. Little, Can. J. Phys. 37 (1959), 334-349. 


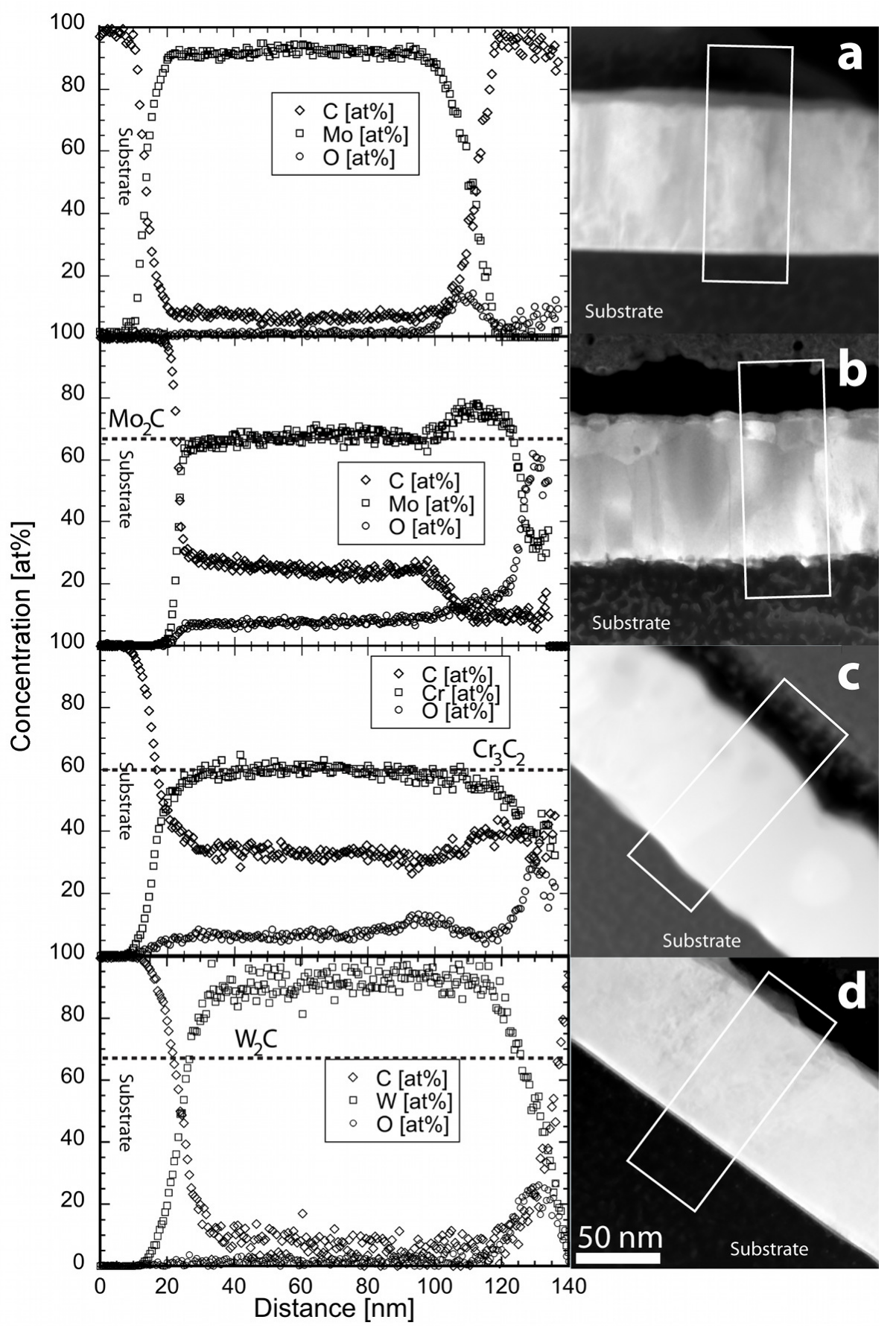

FiguRE 1: TEM cross-sections and EDX linescans across the layers of Mo (before, a, and after, b), $\mathrm{Cr}(\mathrm{c})$ and $\mathrm{W}(\mathrm{d})$ after heat treatment. 


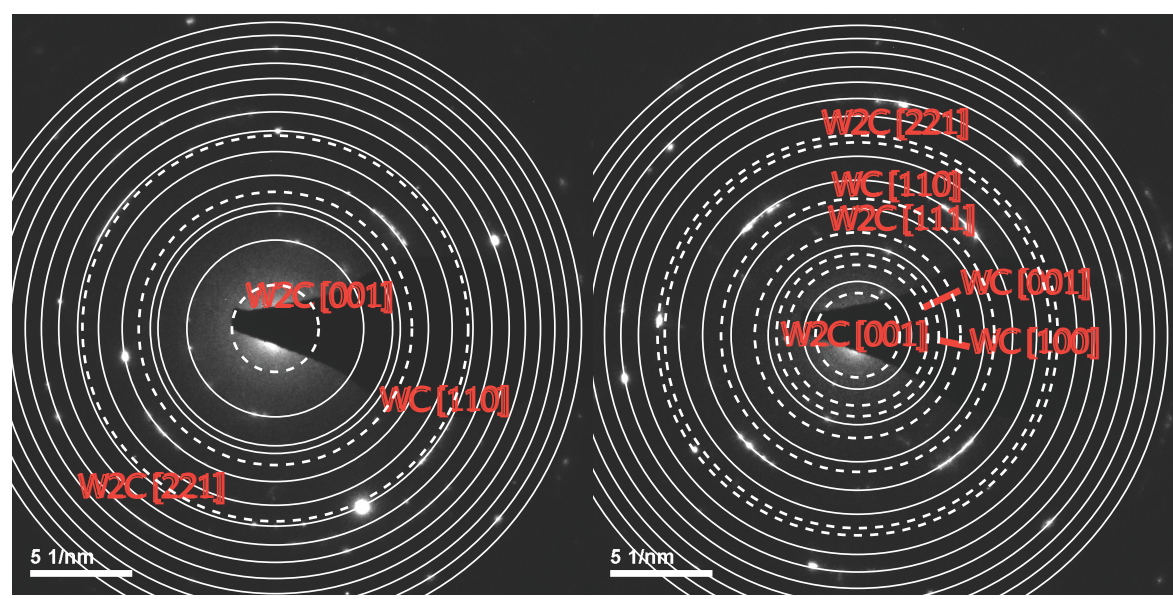

Figure 2: Two examples of diffraction patterns obtained from the $\mathrm{W}$ layer on diamond after heat treatment. The white circles indicate reciprocal distances related to metallic tungsten and tungsten oxide. The dashed white circles indicate reciprocal distances related to tungsten carbides, $\mathrm{W}_{2} \mathrm{C}$ or $\mathrm{WC}$, with corresponding reciprocal indexes indicated in red. 

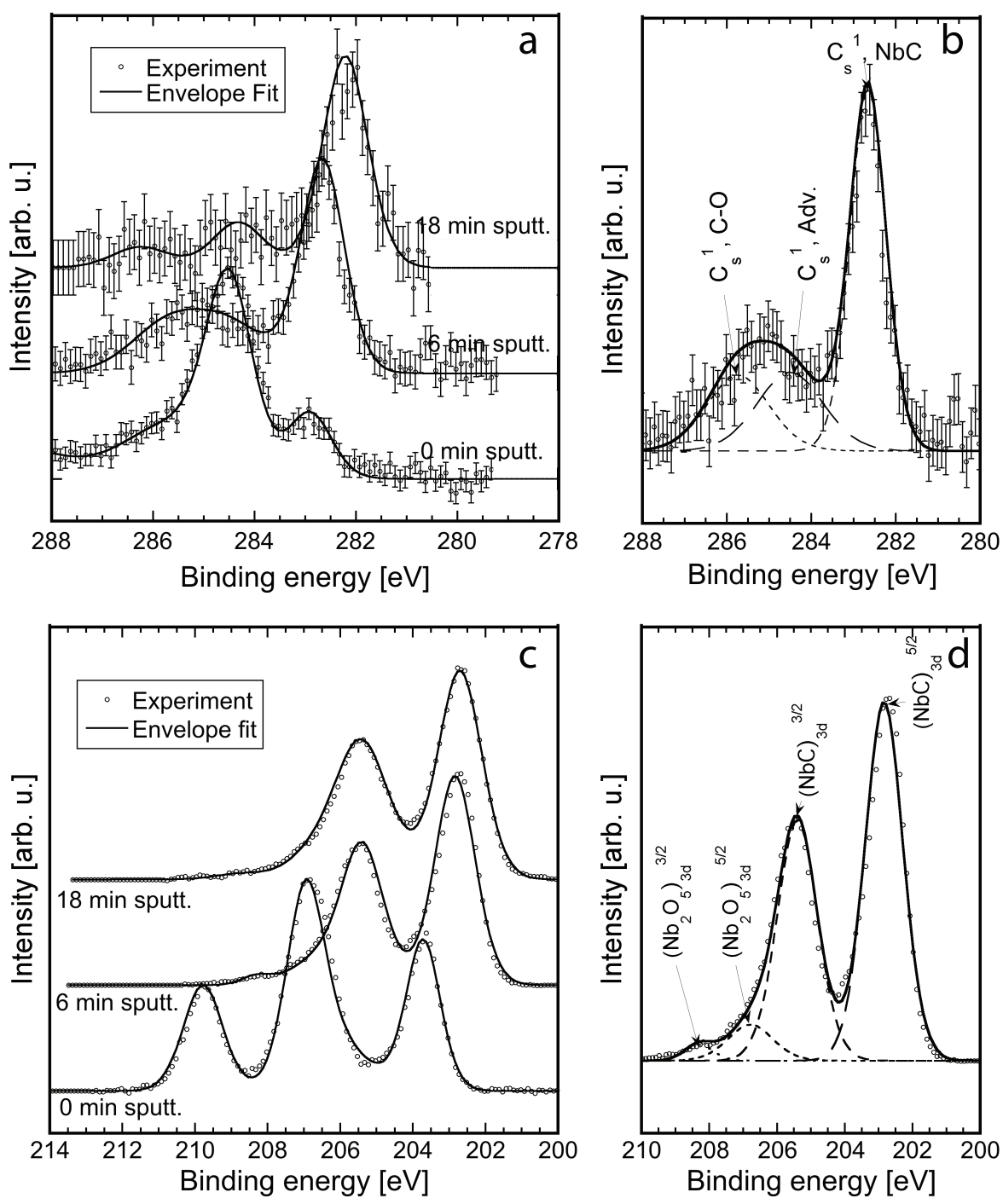

FiguRE 3: XPS spectra recorded after 0,6 and 18 minutes etching of the sample surface using $\mathrm{Ar}$ ions at an energy of $0.5 \mathrm{keV}$. (a) shows the spectrum around the $\mathrm{C}_{s}^{1}$ energies along with the envelope fit obtained using Gaussian-Lorentzian fitting curves. (b) shows a detailed view of the spectrum around $\mathrm{C}_{s}^{1}$ after 6 min sputtering to show the subpeaks used in the fitting. (c) shows the spectrum around the $\mathrm{Nb}_{d}^{3}$ energies along with the envelope fit obtained using Gaussian-Lorentzian fitting curves. (d) shows a detailed view of the spectrum around $\mathrm{Nb}_{d}^{3}$ with 6 min sputtering to show the subpeaks used in the fitting. In the cases of (a) and (b), as the surface chemistry was rich in $\mathrm{Nb}$ and the mass contrast between $\mathrm{C}$ and $\mathrm{Nb}$ is high, a signal of lower quality was obtained at constant acquisition time. Error bars consisting in the RMS noise of the background signal were added to account for the lower quality of the result. In all other instances, such an error would be smaller than the obtained experimental points. 


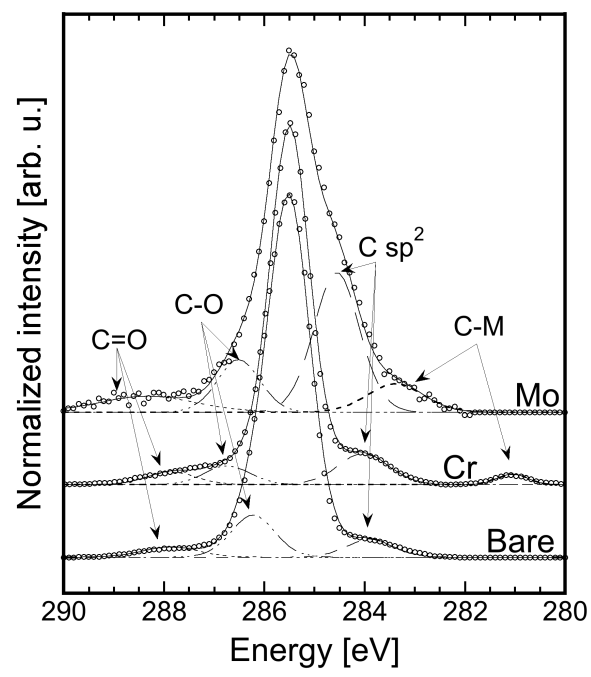

Figure 4: XPS carbon peak of the deposited $\mathrm{Cr}$ and Mo ultrathin film, compared to a bare, $\mathrm{Ar}$ :O plasma treated surface. The subpeaks are indicated by arrows : $\mathrm{sp}^{2} \mathrm{C}, \mathrm{C}$ single bond $\mathrm{O}(\mathrm{C}-\mathrm{O}), \mathrm{C}$ double bond $\mathrm{O}(\mathrm{C}=\mathrm{O})$ and $\mathrm{C}$ carbide $(\mathrm{C}-\mathrm{M})$. The main $\mathrm{sp}^{3} \mathrm{C}$ (diamond) peak lies at $285.5 \mathrm{eV}$ in all cases. 


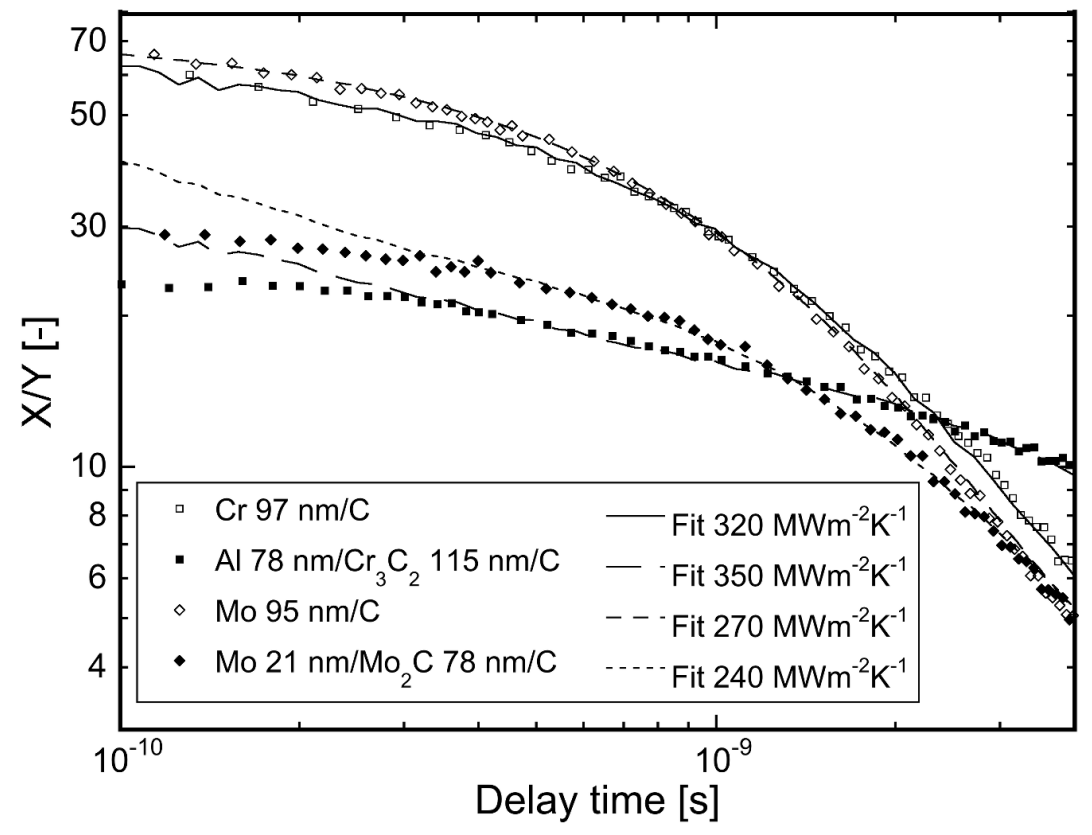

FiguRE 5: Examples of TDTR curves acquired before and after heat treatment for the $\mathrm{Cr}$ / C and Mo / C systems. Error bars are not indicated in the experimental curves as they are smaller than an experimental point. 